\title{
Using Mediating Metacommunication to Improve Accessibility to Deaf in Corporate Information Systems on the Web
}

\author{
Aline da Silva Alves ${ }^{1,2, *}$, Simone Bacellar Leal Ferreira ${ }^{1}$, \\ Viviane Santos de Oliveira Veiga ${ }^{2}$, Ingrid Teixeira Monteiro ${ }^{3}$, \\ and Denis Silva da Silveira ${ }^{4}$ \\ ${ }^{1}$ Universidade Federal do Estado do Rio de Janeiro, Rio de Janeiro, Brazil \\ ${ }^{2}$ Fundação Oswaldo Cruz, Rio de Janeiro, Brazil \\ ${ }^{3}$ Semiotic Engineering Research Group - SERG, PUC-Rio, Rio de Janeiro, Brazil \\ ${ }^{4}$ Universidade Federal Pernambucana, Recife, Brazil \\ aalves@fiocruz.br, simone@uniriotec.br, vsantos@icict.fiocruz.br, \\ dsilveira@ufpe.br, imonteiro@inf.puc-rio.br
}

\begin{abstract}
In general, pre-linguistic deaf bilingual users have difficulty understanding the textual information available in web pages. Therefore, this paper focuses on the use of dialogs mediating the interaction of pre-linguistic deaf in a bilingual organizational context, identify possible breakdowns in communication between both user interface and web page system information, as in the use of mediation dialogues. In that context, we evaluated the interaction of users' activities navigation and data entry in the organizational system, investigating differences in interactive communication system with and without the use of mediation dialogues through tool Web Navigation Helper (WNH). The survey results identified that the development of communication strategies that meet the specific language of deaf pre-linguistic bilingual improves the quality of metacommunication, promoting accessibility during interaction with the system.
\end{abstract}

Keywords: Accessibility, Deafness, Communicability.

\section{$1 \quad$ Introduction}

Usability by itself does not guarantee plain access to all users [1][2]. It is necessary that systems are also oriented to accessibility [3][4][5]. This paper aim to investigate the accessibility needs of bilingual pre-linguistic deaf users, who became deaf before learning to speak and do not have auditory memory skills. Hence, they do not dominate the Portuguese language and may struggle in executing simple tasks in Web, due to the predominance of textual information [6].

Several research works highlight the linguistic difficulties of this population as like: difficulty in understanding Portuguese, due to the process of words signification; "Brazilian Signs Language" (LIBRAS) does not have an own writing system, hence

\footnotetext{
* Corresponding author.
} 
the deaf uses the writing Portuguese during lecture and writing, as a second language [7][8]. A previous work [9] pointed the Semiotic Engineering's Communicability Evaluation Method (CEM) [10] as one of the most efficient methods of accessibility evaluation to deaf users.

Semiotic Engineering (SemEng)is a semiotic theory of Human-Computer Interaction whereby the system's designer communicates with users during the interaction. The systems' interface transmits the designer's vision about who the users are, what they want or need to do, and their preferred way to do it. This special message is called metacommunication [11]. SemEng allows exploring new interaction ways to users with limitations. One of these ways happens through the use of mediation dialogs using the "Web Navigation Helper" (WNH) tool, that provide the user some help messages needed to interact with the system. The dialog creator should know the end user's skills, preferences and language and should be able to adapt the dialogs writing style to the user's linguistic competences.

WNH is a user agent that executes tasks automatically scripted by CoScripter. The dialogs are related to scripts steps that are considered critical to the interaction by the dialog creator. They are displayed during the script execution simultaneously to user navigation [12].

This piece of exploratory research has been based on a case study with multiple units of analysis, thus aiming to verify the use of new communication strategies to minimize the barriers faced by bilingual deaf during web navigation, through the use of mediation dialogs. It was possible to identify the communication breakdowns between interface and user in two different situations: firstly without the WNH mediation, later with the use of mediation dialogs.

The observations were done at the Oswaldo Cruz Foundation (Fiocruz), one of the main research institutions in the health area in Brazil. This foundation has an agreement with the National Federation of Education and Integration of the Deaf (FENEIS), employing 150 deaf workers [13].

To perform the interaction observations and the data collect, eight volunteers took part. CEM was used to identify the communicability breakdowns in the interaction with and without WNH. The analysis compare (1) the users' interaction in navigation activities and data input in an organizational system, investigating comprehension of the designer's communication by the user, by observing the interaction with the original interface of the organization's intranet (without WNH), with (2) the communication of mediation dialogs towards the user (with WNH).

The dialogs were created by a LIBRAS interpreter, giving direct instructions and providing familiar examples about how to interact with the system and to inform data. The texts were written in Portuguese, following a simplified way, as an attempt to translate the LIBRAS signs to written Portuguese.

\section{Web Accessibility and Deafness}

In the web environment, the resources best used as assistive technologies for deaf aim at removing barriers of access to information available in audio through the use of 
subtitles or transcript of all audio content into textual information or Brazilian Sign Language (Libras) [14].

Deaf generally are individuals with compromised verbal comprehension, who have difficulties acquiring oral language naturally [15].

Since in Brazil, there are approximately 5.7 million citizens with hearing impediment, representing $3.38 \%$ of the population [16], it is crucial to recognize the specificities of these users' interaction with information systems in order to minimize barriers that may compromise or prevent the use of information systems.

\section{WNH - The Web Navigation Helper}

Is a web navigation wizard that facilitates and helps users to perform tasks, especially users with limitations through previously created dialogs that mediate user interaction with the interface [12]. Implemented as an extension to Mozilla's Firefox browser, and the tasks are prior automated by CoScripter, macro recorder developed by IBM [12]. Dialogs are created from scripts and are used in end-user interaction with the site's original page [12].

\section{Interface Evaluation under the Perspective of Semiotic Engineering}

In Semiotic Engineering (SemEng) a system interface is seen as a way of communication. The user understands the message in the process of interacting with the interface. This communication is referred as metacommunication and its message is the metamessage [11]. The Communicability Evaluation Method (CEM) is executed sequentially in three steps: tagging, interpretation and creation of the semiotic profile, starting on previous observations (tests) of the users' interaction [17-18-19].

The creation of the semiotic profile, the analysis process is completed with a characterization of the receipt of the metacommunication messages, which consists of the interpretation of the data identified in the previous step, by trying to reconstruct the metamessage that the designer wished to transmit through the interface [11 p.126],[18-19]. In order to reconstruct the metamessage, the interpretations done in the tagging stage allowed the evaluator to assume the designer's role and to answer the following questions: "Who are the users of the systems?"; "What do the users need or have to do?"; "How do they like to do it, and why?"; "How can or should they use it?"; "What's my vision of design?". The Construction of the designer's metamessage for the user should be done through the standard template [11 p.23].

\section{Methodology}

This exploratory research has been based on a case study with multiple units of analysis. Two sessions of observation of interactions were carried out, considering each 
session as a unit of analysis, which allowed a comparison between the results. The research was conducted at Fiocruz and had eight pre-linguistic bilingual deaf participants, requiring two Libras interpreters. To facilitate the identification of the performance of each interpreter during the different stages of the research, they will be identified as interpreter_Feneis and interpreter_Fiocruz.

The research comprised three (3) stages: (5.1) Preparation of the test environment; (5.2) observation of the users' interaction; (5.3) analysis of results through the Communicability Evaluation Method (CEM)

\subsection{Preparation of the Test Environment}

Users participants were selected with the following characteristics: deep pre-linguistic deaf, bilingual literacy, having Libras as a first language and Portuguese as a second, frequency of computer use of over three years and level of education from elementary school (in order to make the knowledge of the Portuguese language homogeneous).

The research involved the participation of eight individuals identified as U-1, U-2, U-3, U-4, U-5, U-6, U-7, U-8. Five participants had completed high school, only one was in elementary school, another was in high school, and another was in college.

It was determined that testing would take place at Fiocruz, in a controlled environment, created specifically for the research. The scenario was developed so that users could carry out the actions sequentially, allowing the identification of breakdowns in the interpretation of the information system. The task defined was to open a request to technical support staff informing problems with the mouse. Table 1 shows the shortest path users could take to complete the task.

Table 1. Shortest path to task completion

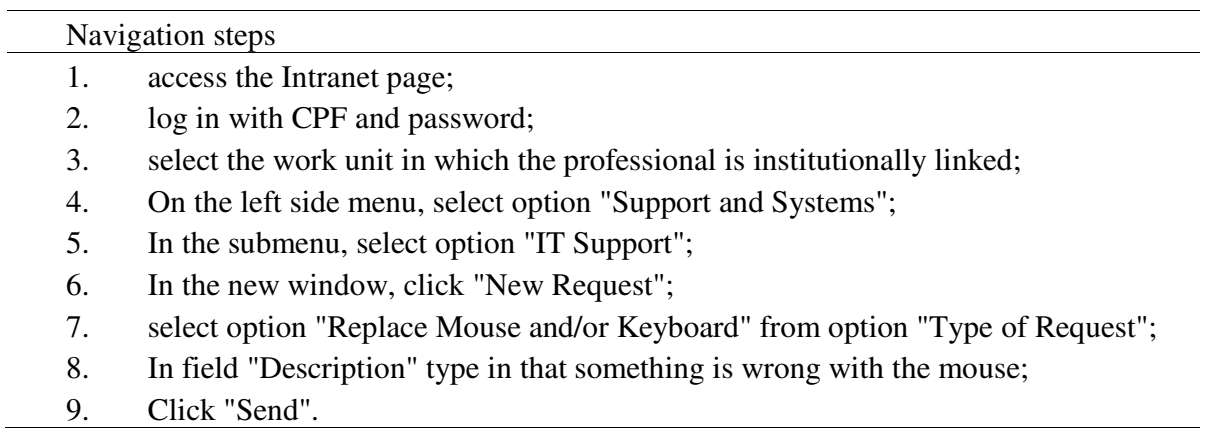

Selection of Voluntary Interpreter for the Creation of Mediation Dialogs. The participant interpreter_Feneis helped conduct the tests concerning the first unit of analysis of the case study where deaf participants interacted with the original interface of the system, i.e., without the help of the WNH. The invitation was due to the fact that her has professional experience, with four years of work dedicated to social assistance oriented to the deaf, proficiency certified PROLIBRAS. 
Creation of Mediation Dialogs by the Volunteer Interpreter. This task was based on five dialogs, two special, welcome and closing dialogs, and three mediation dialogs. The entire process, including the reception and interviews lasted 68 minutes.

\subsection{Observation of the Users' Interaction}

Observations and analysis of the results were performed by two evaluators, beginners in the application of the CEM. The synergy between experience and expertise of the evaluators, allowed to identify communication breakdowns. One with experience in accessibility and usability and another with knowledge of deaf culture and Libras, here identified as interpreter_Fiocruz.

The content of the testing scenario and consent form were translated into Libras for further reading and signing. The tests took place in the Public Health Library of Fiocruz, in a controlled environment. Two interviews were conducted: one before the tests which aimed to collect information about users' experiences in using computers and Internet access, and another after the test, which aimed to clarify doubts that could influence the tagging stage and elucidate the participant's general impressions on the system. An interview with deaf consists of four stages: reading, by the interpreter, of questionnaire questions that are in Portuguese; translation of questions to Libras, also performed by the interpreter; answers of respondents, in Libras, writing and translation into Portuguese of responses of the deaf, a task performed by the interpreter.

\subsection{Analysis}

The Communicability Evaluation Method (CEM) of EngSem was used, and consisted of the following phases: tagging, interpretation and creation of the semiotic profile. Detailed in the next section.

\section{Analysis of Results Through the CEM}

This phase aims to present the results of each of the units of analysis of the case study conducted based on the Communicability Evaluation Method (CEM).

\subsection{Analysis of the Results of Users' Interaction without the Use of WNH}

Tagging. This phase consisted of identifying the breakdowns in the communication of the system's original interface with the user, chosen from a set of thirteen possible communicability expressions (tags) proposed by the CEM. Initially, the evaluators analyzed 106 minutes of video of interaction between system and users along with the notes taken by the researcher. Then they were compared with the responses provided by participants when questions were conducted online, through the task of updating the registration data.

Figure 1 shows the frequency of the tags present in the task as well as the total tags per user. During the tagging phase, no user behaviors were observed that would lead 
to the assignment of tags: "What's this?", "Where am I?", "Looks fine to me.", "I can do otherwise", "Thanks, but no, thanks.", proposed by the CEM, therefore, these were not presented in Figure 1 .

\begin{tabular}{|c|c|c|c|c|c|c|c|c|c|c|}
\hline Tag/Users & $\begin{array}{l}\text { Type of } \\
\text { Failure }\end{array}$ & U-1 & $\mathrm{U}-2$ & U-3 & U-4 & U-5 & U-6 & U-7 & U-8 & Tag Frequency \\
\hline I give up. & Complete & 1 & 1 & 1 & 1 & 1 & 1 & & 1 & 7 \\
\hline I can do otherwise & Partial & & 2 & 2 & & & & & & 4 \\
\hline What happened? & & 1 & 1 & 2 & 1 & & 1 & & & 6 \\
\hline Where is it? & & 2 & & 4 & 3 & 4 & 4 & & 2 & 19 \\
\hline What now? & & 3 & & & & & & & 2 & 5 \\
\hline Oops! & Temporary & 1 & & & & & & & & 1 \\
\hline Help! & & 2 & 3 & 4 & 3 & & 3 & 1 & 2 & 18 \\
\hline $\begin{array}{c}\text { Why doesn't it } \\
\text { work? }\end{array}$ & & & 1 & & & & & & & 1 \\
\hline
\end{tabular}

Fig. 1. Support request task tagging (Source: data collection)

Interpretation. Tag "I give up." was identified as the most prominent, with seven occurrences. It is classified in the category of complete failures, pointing out questions concerning the interpretation of interface language expressions. During navigation, before giving up, a higher incidence was identified for tag "Where is it?", then tag "Help!", respectively with nineteen and eighteen occurrences, classified as temporary failures, which together account for $60 \%$ of occurrences.

Creation of the Semiotic Profile. The metamessage of the organizational system is: "In my interpretation, you are a user employee of Fiocruz who has experience in interacting with computers and is fluent in Portuguese. I understand that you would like to use the Intranet to solve specific problems like making requests to the IT technical support team in a practical and fast manner. I also realized that the designer sought to reach only the listeners group, excluding the deaf who are potential users of the system."

Evaluation Results. It's concluded that the deaf - even with experience in using computers - have difficulty in understanding the linguistic terms present on the interface of organizational systems that prevent them from performing simple tasks. Only one participant reached the conclusion of the task correctly. 


\subsection{Analysis of the Results of Users' Interaction with the Use of WNH}

Tagging. This stage consisted of identifying the communicability breakdowns focusing on mediation dialogs, considering only mediation dialogs created, by dividing the same sub-stages performed in the tagging of stage 6.1. A total of 118 minutes of video of interaction between users and the system were analyzed as well as notes taken by the researcher, comparing the answers provided by users through mediation dialogs, with those provided by the users when questions were made by interpreter_Feneis. Some important observations are emphasize, organized by mediation dialogs, extracted during task analysis. It's observed that, to present signals in Libras verbatim, by convention, words in Portuguese are used in capital letters [8].

After reading the welcome dialog, participants U-3 and U-6 requested help from the interpreter ("Help!"), not knowing how to proceed with completion, because they didn't know the word "Continue", as illustrated in Figure 2. After clarification of the meaning of the word, participants continued the task.

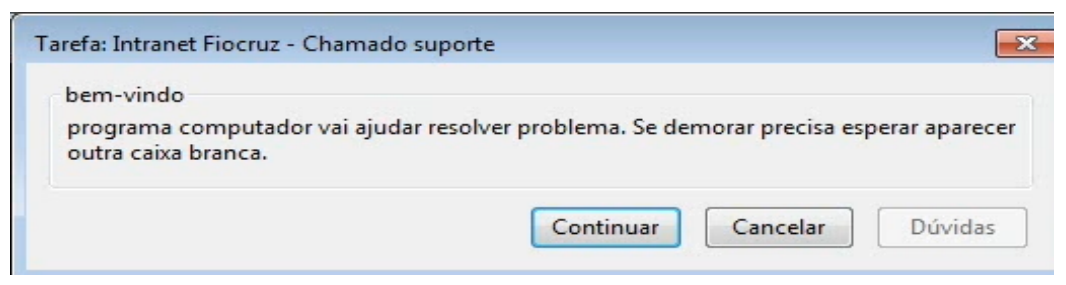

Fig. 2. Welcome dialog of task to request support in WNH (Source: data collection)

User U-1 found the execution of CoScripter slow, noting: "SLOW AS A TURTLE." It was necessary to explain to the user the reason for the delay, resulting from the execution of six steps of CoScripter.

In the second dialog, illustrated in Figure 3, participant U-6 initially reported that the monitor presented problems, typing the word "MONITOR". They reread the test scenario, and added the words "PROBLEM WITH MOUSE!" Completing the field with the information: "MONITOR HAS PROBLEM WITH MOUSE!" It was observed that users understood the question correctly and tags were not assigned to these behaviors.

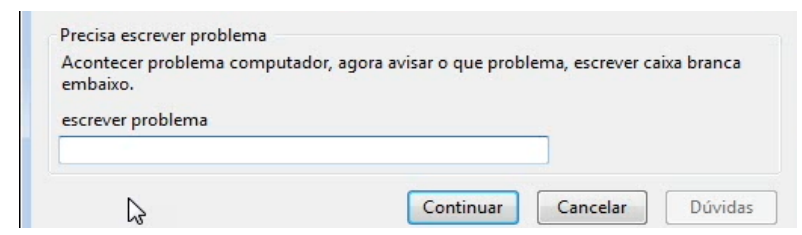

Fig. 3. Mediation dialog of field "error description"(Source: data collection)

Participants U-1, U-4, U-5 and U-7 successfully completed the task and had no doubts on other dialogs, presented in Figure 4. 


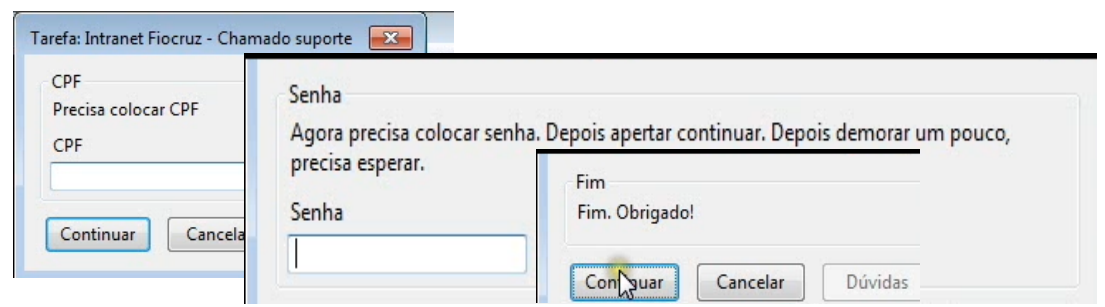

Fig. 4. Mediation dialogs that presented no doubts (Source: data collection)

Upon completion of the task, participant U-8 spontaneously observed that, with the use of WNH, the task was completed more quickly and with greater ease.

Table 3 presents the frequency of tags in a consolidated manner. During the tagging phase, no behaviors were observed that would lead to the assignment of tags: "I give up.", "What's this?", "I can do otherwise", "Where is it?", "Now what?", "Oops!", "I can't do it this way." , "Why doesn't it work?", "Looks fine to me", "Where am I?","What happened?". Not being presented in Figure 5.

\begin{tabular}{|c|c|c|c|c|c|c|c|}
\hline Tag/Users & $\begin{array}{l}\text { Type of } \\
\text { Failure }\end{array}$ & U-1 U-2 & U-3 U-4 U-5 & $\mathrm{U}-6$ & $\begin{array}{c}\text { U- } \\
7\end{array}$ & U-8 & Tag Frequency \\
\hline No, but no, thanks. & Partial & 1 & & & & 1 & 2 \\
\hline Help! & Temporary & 1 & 1 & 1 & & & 3 \\
\hline
\end{tabular}

Fig. 5. Tags present in the task using mediation dialogs (Source: data collection)

Interpretation. It was observed that users approved the interaction with the tool, as a consequence, fewer communication breakdowns of communication, highlighting: some participants did not read the welcome dialog, others did not know the meaning of the word "Continue" considered key to perform the task and the difficulty of the deaf in expressing themselves in Portuguese.

Creation of the Semiotic Profile. The metamessage of the mediation designer is: "In my interpretation, you are a user employee of Fiocruz who has experience in interacting with computers and is not fluent in Portuguese, having Libras as a first language and Portuguese as a second language. I understand that you would like to use the Intranet to solve specific problems like making requests to the IT technical support team in a practical and fast manner. Thus, I used features that seek to optimize the task of navigating between different pages in the system, through the task automation feature, and as you have difficulties in reading and interpreting Portuguese, I used mediation dialogs that respected your language skills."

Analysis of Results. From the characterization of metamessage, it was realized that the use of mediation dialogs followed a design oriented towards the accessibility of pre-linguistic bilingual deaf users without excluding listeners users that use the system. 
The participants understood and interpreted most mediation dialogs, but have had limitations when writing. In such cases, communicability tags were not assigned. The use of mediation dialogs can be considered as a tool to encourage reading, allowing the interpretation of texts, making them more autonomous and participative.

The constancy of similar results obtained during the analysis indicates that many of the communicability breakdowns present in the mediation dialogs could have been minimized with the implementation of a pretest to evaluate the quality of the dialogs created by the volunteer interpreter.

\section{Conclusion}

This exploratory research has been based on a case study with multiple units of analysis, aiming to evaluate the use of mediation dialogs in the interaction of pre-linguistic bilingual, profound deaf users within an organizational context, in order to identify communication breakdowns in communication between interface and user without the use of mediation dialogs.

Concepts related to hearing impairment were discussed, particularly, the difficulty deaf people have in learning Portuguese as a second language, web accessibility and interaction difficulties and a brief introduction about the Theory of Semiotic Engineering.

The stage of data collection and observation involved the participation of eight volunteers. The CEM of SemEng was used to compare the interaction of users in navigation activities and input of data, investigating the qualities and breakdowns in the communication.

The interaction without WNH was challenging to all users: only one of them achieved the proposed tasks. Using WNH, in spite of few difficulties, all users completed the tasks successfully. The interaction with WNH revealed interesting issues related to communication between dialog creators and users. For example, as the interpreter knew well all users she was able to give real and contextualized examples, so really helping them during the data input. It was also observed the impact of the WNH mediation in the process of communication. The text inside dialogs was a way of the interpreter represents herself through software. It was collected several evidences of her self-expression and self-representation, by observing how users directly communicated with her, as if she was "there". Another study with WNH is dedicated to deeply discuss this issue [20].

The results of research allowed identifying that the developing of communicative strategies that respect the linguistic specificities of deaf users, could improve the quality of metacommunication, promoting the accessibility during the interaction with the system.

\section{References}

1. Hanson, V.L.: The User Experience: Designs and Adaptations. In: Proceedings of the 2004 International Cross-Disciplinary Workshop on Web Accessibility (W4A), pp. 1-11. ACM Press, New York (2004)

2. Nielsen, J.: Projetando websites. Campus, Rio de Janeiro (2000) 
3. Leal Ferreira, S.B., Santos, R., Silveira, D.S.: Panorama da Acessibilidade na Web Brasileira. Revista de Controle e Administração III (2), 205-234 (2007)

4. Leporini, B., Paternò, F.: Applying web usability criteria for vision-impaired users: does it really improve task performance? International Journal of Human-Computer Interaction 24(1), 17-47 (2008)

5. Nicholl, A.R.J.: O Ambiente que promove a inclusão: conceitos de acessibilidade e usabilidade. Revista Assentamentos Humanos 3(2), 49-60 (2001)

6. Corradi, J.A.M.: Ambientes informacionais digitais e usuários surdos: questões de acessibilidade. Mestre. Dissertação Mestre. Universidade Estadual Paulista, Marília-SP (2007)

7. Kozlowski, L.: O modelo educacional Bilingüe no INES. Revista Espaço (18-19), 102-105 (2002)

8. Felipe, T.: Libras em contexto: curso básico: livro do estudante. WalPrint, Rio de Janeiro (2007)

9. Oliveira, D.R.R., Dias, J.S., Muller, M.F., Pinto, F.C., Souza, G.L., Prates, R.O., Bernadino, E.L.A.: Avaliação da Acessibilidade do Sítio da Receita Federal para Deficientes Auditivos. In: Simpósio de Fatores Humanos em Sistemas Computacionais, Belo Horizonte, MG, Brasil (2010)

10. Souza, C.S., Leitão, C.F.: Semiotic engineering methods for scientific research in HCI. Morgan \& Claypool Publishers, California (2009)

11. Souza, C.S.: The semiotic engineering of human-computer interaction. The MIT Press, Cambridge (2005)

12. Monteiro, I.T., Souza, C.S.: Embedded Cultural Features in the Design of an Accessibility Agent for the Web. In: Proceedings of the 6th International Conference on Universal Access in Human-Computer Interaction Design for all and Einclusion, HCI, Orlando, EUA, pp. 295-304 (2011)

13. Federação Nacional de Educação e Integração dos Surdos. Fiocruz: além da porta de emprego: a visão do profissional surdo. Revista da Feneis 7(31), 17-21 (2007)

14. Ferreira, S.B.L., Nunes, R.: e-Usabilidade. LTC, Rio de Janeiro (2008)

15. Sacks, O.: Vendo vozes: uma viagem ao mundo dos surdos. Companhia das Letras, São Paulo (1998)

16. Instituto Brasileiro de Geografia e Estatística.: Censo 2010: Dados referentes à deficiência (2010) http: / / www. censo2010.ibge.gov.br/calendarioresul.php

17. Oliveira, D.R.R., Dias, J.S., Muller, M.F., Pinto, F.C., Souza, G.L., Prates, R.O., Bernadino, E.L.A.: Avaliação da acessibilidade do sítio da receita federal para deficientes auditivos. In: IX Simpósio de Fatores Humanos em Sistemas Computacionais, pp. 91-102. SBC, Belo Horizonte (2010)

18. Souza, C.S., Leitão, C.F.: Semiotic engineering methods for scientific research in HCI. Morgan \& Claypool Publishers, Princeton (2009)

19. Prates, R.O., Souza, C.S., Barbosa, S.D.J.: A method for evaluating the communicability of user interfaces. Interactions 7(1), 31-38 (2000)

20. Monteiro, I.T., Souza, C.S.: The representation of self in mediated interaction with computers. In: Proceedings of IHC 2012 XI Simpósio Brasileiro de Fatores Humanos em Sistemas Computacionais, Cuiabá, Brasi, pp. 5-9 (2012) 